\title{
Tumor deposit indicates worse prognosis than metastatic lymph node in gastric cancer: a propensity score matching study
}

\author{
Jianan Tan ${ }^{1 \#}$, Bin Yang ${ }^{1 \#}$, Zhimeng $\mathrm{Xu}^{2}$, Shengning Zhou ${ }^{1}$, Zhitao Chen ${ }^{1}$, Jing Huang ${ }^{1}$, Han Gao ${ }^{1}$, \\ Senyou Zheng ${ }^{1}$, Liqiang Wen ${ }^{1}$, Fanghai Han ${ }^{1}$ \\ ${ }^{1}$ Department of Gastrointestinal Surgery, Sun Yat-sen Memorial Hospital, Sun Yat-sen University, Guangzhou 510000, China; ${ }^{2}$ Department of \\ Biostatistics and Epidemiology, School of Public Health, Sun Yat-sen University, Guangzhou 510000, China \\ Contributions: (I) Conception and design: F Han, J Tan; (II) Administrative support: F Han, B Yang; (III) Provision of study materials or patients: B \\ Yang, S Zhou, Z Chen; (IV) Collection and assembly of data: J Huang, H Gao, S Zheng; (V) Data analysis and interpretation: J Tan, Z Xu, L Wen; \\ (VI) Manuscript writing: All authors; (VII) Final approval of manuscript: All authors. \\ \#These authors contributed equally to this work. \\ Correspondence to: Fanghai Han. Departments of Gastrointestinal Surgery, Sun Yat-sen Memorial Hospital, Sun Yat-sen University, 107 Yanjiang \\ Road, East, Guangzhou 510000, China. Email: fh_han@163.com.
}

\begin{abstract}
Background: The prognostic value of tumor deposit (TD) in gastric cancer is controversial. This study aims to investigate the prognostic value of TD.

Methods: The consecutive patients diagnosed with gastric cancer from October 2007 to October 2012 were selected. The patients were divided by whether they suffered TD into two groups. The basic data were comparable between the two groups after propensity score matching (PSM), then survival analysis [overall survival (OS) and cancer-specific survival (CSS)] was applied in two groups. After that, all the patients were divided by pN staging and survival analysis were applied in each subgroup. At last, all patients were divided into TD group, pN1 stage group, pN2 stage group, pN3a, and pN3b stage group, OS and CSS were compared between them. Multivariable competing risk analyses tested association of TD with OS and CSS, before and after PSM.
\end{abstract}

Results: Eight hundred and three patients were concluded. After PSM, 137 patients with TD and 274 patients without TD were selected, the 5-year OS and CSS rates of patients with TD were significantly worse than patients without TD (OS: $19.7 \%$ vs. $42.0 \%, \mathrm{P}<0.001$; CSS: $22.6 \%$ vs. $45.6 \%, \mathrm{P}<0.001$ ). In all patients' survival analysis, the 5 -year OS and CSS rates of TD group were comparable with pN3a group (OS: $19.7 \%$ vs. $25.3 \%, \mathrm{P}=0.221$, CSS: $22.6 \%$ vs. $30.1 \%, \mathrm{P}=0.092$ ) and $\mathrm{pN} 3 \mathrm{~b}$ group (OS: $19.7 \%$ vs. $19.6 \%$ $\mathrm{P}=0.349$, CSS: $22.6 \%$ vs. $23.5 \%, \mathrm{P}=0.452$ ). Meanwhile, on multivariable cox regression analyses, the presence of TD significantly reduces the OS and CSS of patients in gastric cancer.

Conclusions: TD has a marked impact on the prognosis of gastric cancer. Even patients with TD had the same prognosis with $\mathrm{pN} 3$ stage.

Keywords: Tumor deposit (TD); gastric cancer; prognosis; TNM staging

Submitted Sep 09, 2019. Accepted for publication Sep 18, 2019.

doi: $10.21037 /$ atm.2019.10.33

View this article at: http://dx.doi.org/10.21037/atm.2019.10.33

\section{Introduction}

The concept of TD was proposed by scientist Gabriel as early as 1935 . He discovered and reported the tumorlike nodular masses besides the colorectal tumor and in the fat tissue of mesocolon and mesorectum (1). With the deepening of research, the conclusion that TD is a poor prognosis for colorectal cancer has been confirmed eventually (2-4) and was finally included in the N1c stage in colorectal cancer separately in the 7 th edition of the TNM staging (5). Puppa et al. reported that TD not only existed 
in colorectal cancer but also other solid malignant tumors such as gastric cancer, cholangiocarcinoma, and pancreatic cancer (6). However, the prognostic value of TD in gastric cancer is controversial. In the 8th edition of TNM staging, TD tend to be considered as metastatic lymph nodes (7), while there is some studies that indicate that TD should be regarded as serosal invasion $(8,9)$. This study aims to invest the value of TD in the prognosis of gastric cancer through propensity score matching (PSM).

\section{Methods}

\section{Data source}

A prospective retrospective database was applied by this study, including the consecutive gastric cancer patients with curative resection from October 2007 to October 2012 in Sun Yat-sen Memorial Hospital. There is no intentional inclusion or exclusion. All patients diagnosed with gastric cancer at in our institution were registered with the followup data, including survival state, causes of death, and the follow-up times. Follow up data were recorded through telephone, email, and outpatient.

Patients diagnosed with gastric cancer from October 2007 to October 2012 were selected along with their clinicopathological data, including sex, age, method of therapy, tumor deposits (TDs), lymphatic nodes, depth of invasion, differentiated degree, the follow-up date, overall survival (OS), and cancer-specific prognosis. All the selected patients are performed curative tumor resection with lymph node dissection, but not including gastric cancer resection and combined metastatic organ resection. Patients with malignancies other than gastric adenocarcinoma, or recurrent gastric cancer, or gastric stump cancer, or accepted neoadjuvant chemotherapy, patients with the number of LN detection less than 15 were excluded. Finally, a total of 803 patients were included. According to the 8th edition of TNM staging in gastric cancer (10), only when center of tumor is $2 \mathrm{~cm}$ away from the gastroesophageal junction, the tumor should be including in TNM staging for gastric cancer.

\section{Definition of TD}

TD was defined that discrete foci of tumor found in the perigastric fat or adjacent ligament away from the primary tumor, without evidence of residual lymph node tissue but within the lymph drainage area of the primary tumor.
The examination for TD was dependent on two pathology professors at Sun Yat-sen Memorial Hospital by a doubleblind method, and if there is a disagreement between them, the third pathology professor will diagnose it. The depth of invasion and lymphatic nodes metastasis were classified by 8th edition of TNM staging system.

\section{Statistical analysis}

First, descriptive statistics were used to describe the participants' clinicopathologic characteristics and other baseline variables. Median (range) values were used to describe continuous variables, and Ratio was used to describe categorical variables. Mann-Whitney $U$ test (for nonparametric distribution), and chi-square tests or Fisher exact test (for categorical variables) were used to assess differences between TD-group and non-TD-group before and after PSM.

To estimate propensity score, logistic regression analysis was performed using nearest neighbor matching. The ratio for matching was $1: 2$ using a caliper of width equals to 0.2 of the standard deviation of the logit of the propensity score.

Survival analysis was performed using the Kaplan-Meier method with log-rank analysis to compare survival functions between groups. Multivariable cox regression analysis was applied to consider the association between TD and prognosis. Patients who died from other cause or still were alive were treated CSS. Survival rates between groups at 60 months were reported.

Statistical significance was considered at $\mathrm{P}<0.05$. All analyses were performed using the $\mathrm{R}$ language version 3.4.2.

\section{Results}

\section{Patient's clinicopathologic characteristics before and after propensity score match}

The 803 patients were concluded; there were 137 patients with TD and 666 patients without TD; their characteristics were recorded in Table 1. Overall, TD was found in 137 patients (20.6\%), and there are 666 patients without TD; There was no significant difference in gender, age, tumor location, and chemotherapy rates between TD and nonTD patients (all $\mathrm{P}$ value $>0.05$ ). However, patients with TD were more likely in high level pT stage (pT4a: $44.5 \%$ vs. 
Table 1 Clinicopathologic demographics of included patients before and after Propensity Score Matching

\begin{tabular}{|c|c|c|c|c|c|c|c|c|}
\hline Variables & \multicolumn{4}{|c|}{ Before PSM } & \multicolumn{4}{|c|}{ After PSM } \\
\hline Male & $543(67.6)$ & $452(67.9)$ & $91(66.4)$ & & 281 (68.3) & $190(69.3)$ & $91(66.4)$ & \\
\hline \multicolumn{2}{|c|}{ Tumor location, n (\%) } & & & 0.414 & & & & 0.361 \\
\hline Lower & $363(45.2)$ & $299(44.9)$ & $64(46.7)$ & & $185(45.0)$ & $121(44.2)$ & $64(46.7)$ & \\
\hline Middle & $199(24.8)$ & $161(24.2)$ & $38(27.7)$ & & $103(25.1)$ & $65(23.7)$ & $38(27.7)$ & \\
\hline High & $512(63.7)$ & $464(69.7)$ & $48(35.0)$ & & $161(39.2)$ & $113(41.2)$ & $48(35.0)$ & \\
\hline Low & 291 (36.3) & $202(30.3)$ & $89(65.0)$ & & $250(60.8)$ & $161(58.8)$ & $89(65.0)$ & \\
\hline \multicolumn{2}{|l|}{ pT stage, n (\%) } & & & $<0.001$ & & & & 0.163 \\
\hline pT1 & $112(13.9)$ & $107(16.0)$ & $5(3.6)$ & & $9(2.1)$ & $4(1.5)$ & $5(3.6)$ & \\
\hline pT2 & $100(12.5)$ & $85(12.8)$ & $15(10.9)$ & & $41(10.0)$ & $26(9.5)$ & $15(10.9)$ & \\
\hline рT3 & 187 (23.3) & $164(24.6)$ & $23(16.8)$ & & $82(20.0)$ & $59(21.5)$ & $23(16.8)$ & \\
\hline $\mathrm{pT} 4 \mathrm{a}$ & $294(36.6)$ & $233(35.0)$ & $61(44.5)$ & & $200(48.7)$ & $139(50.7)$ & $61(44.5)$ & \\
\hline pN3a & $115(14.3)$ & $83(12.5)$ & $32(23.4)$ & & $102(24.8)$ & $70(25.5)$ & $32(23.4)$ & \\
\hline $\mathrm{pN} 3 \mathrm{~b}$ & $88(11.0)$ & $51(7.7)$ & $37(27.0)$ & & $87(21.2)$ & $50(18.3)$ & $37(27.0)$ & \\
\hline \multicolumn{2}{|c|}{ Chemotherapy, n (\%) } & & & 0.712 & & & & 0.093 \\
\hline Yes & $484(60.3)$ & $399(59.9)$ & $85(62.0)$ & & 279 (67.9) & $194(70.8)$ & $85(62.0)$ & \\
\hline No & $319(39.7)$ & $267(40.1)$ & $52(38.0)$ & & $132(32.1)$ & $80(29.2)$ & $52(38.0)$ & \\
\hline \multicolumn{2}{|c|}{ Tumor size, n (\%) } & & & $<0.001$ & & & & 0.343 \\
\hline$<5 \mathrm{~cm}$ & $451(56.2)$ & $395(59.3)$ & $56(40.9)$ & & $183(44.5)$ & $127(46.4)$ & $56(40.9)$ & \\
\hline$\geq 5 \mathrm{~cm}$ & $352(43.8)$ & $271(40.7)$ & $81(59.1)$ & & $228(55.5)$ & $147(53.6)$ & $81(59.1)$ & \\
\hline
\end{tabular}

TD, tumor deposit; PSM, propensity score matching; IQR, interquartile range. 

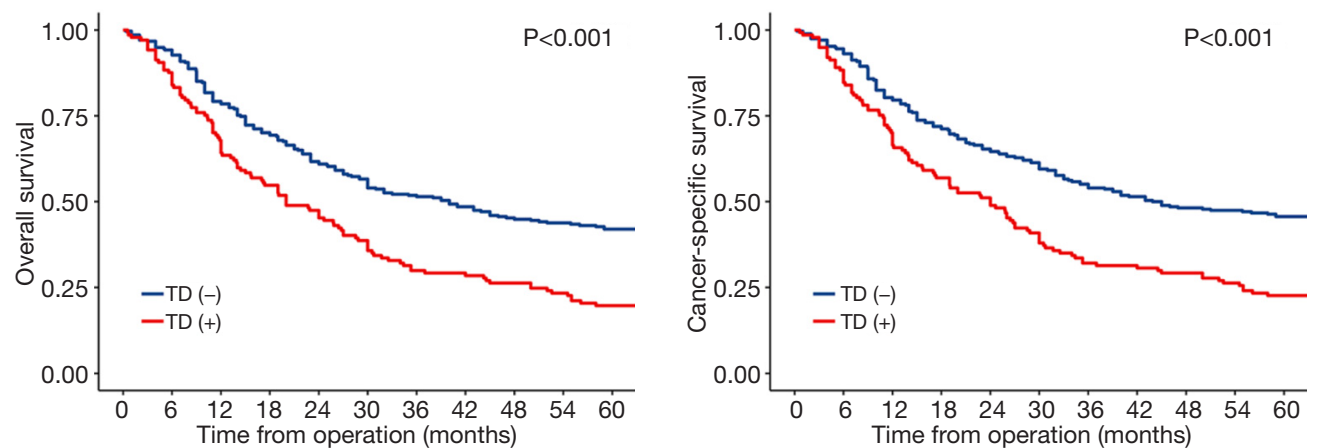

Figure 1 OS and CSS between TD and non-TD group in the matched cohort. OS, overall survival; CSS, cancer-specific survival; TD, tumor deposit.

35.0\%; pT4b: $24.2 \%$ vs. $11.6 \%$ ), pN stage (pN3a: $23.4 \%$ vs. 12.5\%; pN3b: $27.0 \%$ vs. $7.7 \%$ ), poor differentiated degree ( $65.0 \%$ vs. $30.3 \%$ ) and tumor size ( $\geq 5 \mathrm{~cm}: 59.1 \%$ vs. $40.7 \%$ ) compared to patients without TD.

After a propensity score match of 1:2, 137 patients with TD and 274 patients without TD were obtained, and there was no significant difference in between the two groups considering gender, age, tumor location, differentiated degree, $\mathrm{pT}$ stage, $\mathrm{pN}$ stage, chemotherapy, and tumor size (Table 1).

\section{Survival analysis in the matched cohort}

Long term outcomes were performed between the selected patients, the median follow-up period for OS was 80 (95\% CI, 70-88) months in the TD group and 75 (95\% CI, 71-76) months in the non-TD group. The median followup period for CSS was 40 (95\% CI, 33-47) months in the TD group and 67 (95\% CI, 66-68) months in the non-TD. The 5 -year OS rates of TD group and non-TD group were $19.7 \%$ (95\% CI, $14.1-27.6 \%$ ) and $42.0 \%$ (95\% CI, $36.5-$ $48.2 \%$ ), the 5 -year cancer-specific survival (CSS) rates of TD group and non-TD group were $22.6 \%$ (95\% CI, 16.6$30.8 \%$ ) and $45.6 \%$ (95\% CI, 40.1-51.9\%) (Figure 1). Both OS and CSS of patients with TD were both significantly worse than patients without TD $(\mathrm{P}<0.001, \mathrm{P}<0.001)$. Multivariable Cox regression analyses in matched cohort also showed that TD was associated with poor OS and CSS (Tables 2 and 3, $\mathrm{P}<0.001$ ).
Table 2 Multivariable cox regression analysis of OS in the matched cohort

\begin{tabular}{|c|c|c|c|c|}
\hline Variables & HR & $\begin{array}{l}95 \% \mathrm{Cl} \\
\text { lower }\end{array}$ & $\begin{array}{c}95 \% \mathrm{Cl} \\
\text { upper }\end{array}$ & $P$ value \\
\hline $\begin{array}{l}\text { Gender (male vs. } \\
\text { female) }\end{array}$ & 0.911 & 0.689 & 1.205 & 0.514 \\
\hline Age & 0.996 & 0.986 & 1.007 & 0.484 \\
\hline \multicolumn{5}{|l|}{ Tumor location } \\
\hline Lower & Ref & Ref & Ref & Ref \\
\hline Middle & 0.932 & 0.678 & 1.281 & 0.662 \\
\hline Upper & 1.159 & 0.864 & 1.555 & 0.325 \\
\hline $\begin{array}{l}\text { Tumor size }(\geq 5 \\
\text { vs. }<5 \mathrm{~cm})\end{array}$ & 1.257 & 0.970 & 1.629 & 0.084 \\
\hline $\begin{array}{l}\text { Differentiated } \\
\text { (high vs. low) }\end{array}$ & 1.613 & 1.230 & 2.115 & $<0.001$ \\
\hline Chemotherapy & 0.091 & 0.065 & 0.126 & $<0.001$ \\
\hline \multicolumn{5}{|l|}{ pT stage } \\
\hline pT1 stage & Ref & Ref & Ref & Ref \\
\hline pT2 stage & 0.617 & 0.216 & 1.763 & 0.368 \\
\hline pT3 stage & 1.442 & 0.554 & 3.755 & 0.453 \\
\hline pT4a stage & 1.857 & 0.739 & 4.664 & 0.188 \\
\hline pT4b stage & 2.813 & 1.090 & 7.257 & 0.032 \\
\hline \multicolumn{5}{|l|}{ pN stage } \\
\hline pNO stage & Ref & Ref & Ref & Ref \\
\hline pN1 stage & 5.920 & 2.710 & 12.933 & $<0.001$ \\
\hline pN2 stage & 5.323 & 2.752 & 10.296 & $<0.001$ \\
\hline pN3a stage & 8.524 & 4.378 & 16.597 & $<0.001$ \\
\hline pN3b stage & 7.999 & 4.030 & 15.877 & $<0.001$ \\
\hline TD & 1.594 & 1.224 & 2.077 & $<0.001$ \\
\hline
\end{tabular}

OS, overall survival; $\mathrm{HR}$, hazard ratio; $\mathrm{Cl}$, confidence interval; TD, tumor deposit. 
Table 3 Multivariable cox regression analysis of CSS in the matched cohort

\begin{tabular}{|c|c|c|c|c|}
\hline Variables & $\mathrm{HR}$ & $\begin{array}{l}95 \% \mathrm{Cl} \\
\text { lower }\end{array}$ & $\begin{array}{l}95 \% \mathrm{Cl} \\
\text { upper }\end{array}$ & $P$ value \\
\hline $\begin{array}{l}\text { Gender (male vs. } \\
\text { female) }\end{array}$ & 1.036 & 0.779 & 1.378 & 0.81 \\
\hline Age & 0.998 & 0.987 & 1.008 & 0.68 \\
\hline \multicolumn{5}{|l|}{ Tumor location } \\
\hline Lower & Ref & Ref & Ref & Ref \\
\hline Middle & 0.997 & 0.719 & 1.382 & 0.984 \\
\hline Upper & 1.113 & 0.824 & 1.503 & 0.484 \\
\hline $\begin{array}{l}\text { Tumor size }(\geq 5 \\
\text { vs. }<5 \mathrm{~cm})\end{array}$ & 1.458 & 1.117 & 1.903 & 0.006 \\
\hline $\begin{array}{l}\text { Differentiated } \\
\text { (high vs. low) }\end{array}$ & 1.743 & 1.314 & 2.312 & $<0.001$ \\
\hline Chemotherapy & 0.117 & 0.086 & 0.161 & $<0.001$ \\
\hline \multicolumn{5}{|l|}{ pT stage } \\
\hline pT1 & Ref & Ref & Ref & Ref \\
\hline pT2 & 0.600 & 0.209 & 1.718 & 0.341 \\
\hline pT3 & 1.494 & 0.567 & 3.936 & 0.417 \\
\hline pT4a & 1.684 & 0.667 & 4.255 & 0.27 \\
\hline pT4b & 3.020 & 1.162 & 7.850 & 0.023 \\
\hline \multicolumn{5}{|l|}{ pN stage } \\
\hline pNO & Ref & Ref & Ref & Ref \\
\hline pN1 & 7.308 & 3.267 & 16.349 & $<0.001$ \\
\hline pN2 & 5.415 & 2.740 & 10.703 & $<0.001$ \\
\hline $\mathrm{pN} 3 \mathrm{a}$ & 8.693 & 4.371 & 17.288 & $<0.001$ \\
\hline $\mathrm{pN} 3 \mathrm{~b}$ & 7.546 & 3.738 & 15.234 & $<0.001$ \\
\hline TD & 1.677 & 1.279 & 2.201 & $<0.001$ \\
\hline
\end{tabular}

CSS, cancer-specific survival; HR, hazard ratio; $\mathrm{Cl}$, confidence interval; TD, tumor deposit.

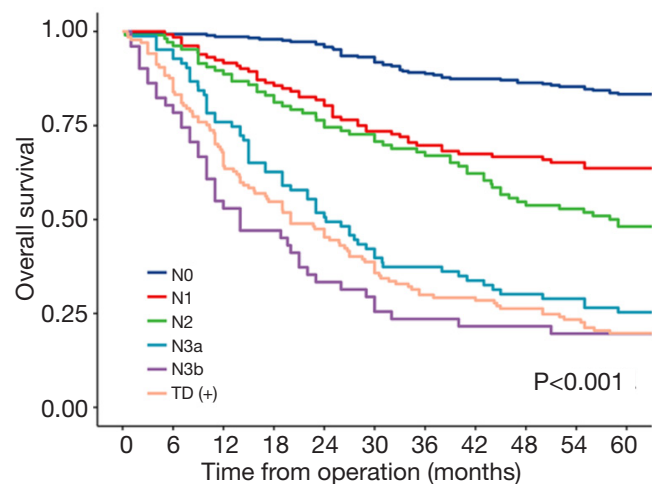

\section{Survival analysis in all patients}

Finally, we try to compare the relationship between the value of TD and lymph node metastasis. We subdivided the patients without TD into 5 categories according to 8 th edition of TNM staging: pN0, pN1, pN2, pN3a, pN3b group. The long term outcomes were recorded in Figure 2, the median follow-up time for OS in $\mathrm{pN} 0, \mathrm{pN} 1, \mathrm{pN} 2, \mathrm{pN} 3 \mathrm{a}$ and pN3b groups were 77 (95\% CI, 74-78) months, 75 (95\% CI, 74-78) months, 73 (95\% CI, 70-78) months, 71 (95\% CI, 65-79) months, 67 (95\% CI, 63-70) months, respectively. the median follow-up time for CSS in pN0, pN1, pN2, pN3a and pN3b groups were 67 (95\% CI, 66-68) months, 66 (95\% CI, 65-67) months, 69 (95\% CI, 67-70) months, 66 (95\% CI, 63-69) months, 62 (95\% CI, 61-65) months, respectively. The 5-year OS rates of TD, pN0, pN1, pN2, pN3a, pN3b group were 19.7\% (95\% CI, 14.1-27.6\%), 83.3\% (95\% CI, 79.2-87.7\%), 63.6\% (95\% CI, 55.9-72.4\%) , 48.1\% (95\% CI, 35.9-58.6\%), $25.3 \%$ (95\% CI, $17.5-36.6 \%$ ), $19.6 \%$ (95\% CI, $11.2-34.2 \%$ ); the 5 -year CSS rates of TD, pN0, pN1, pN2, pN3a, pN3b group were $22.6 \%$ (95\% CI, 16.6-30.8\%), 86.7\% (95\% CI, $82.9-90.7 \%$ ), 68.2\% (95\% CI, 60.7-76.6\%), 51.9\% (95\% CI, 43.2-62.3\%), 30.1\% (95\% CI, 21.7-41.8\%), $23.5 \%$ (95\% CI, $14.3-38.6 \%$ ). Interestingly, the 5 -year OS and CSS rates of TD group were comparable with $\mathrm{pN} 3 \mathrm{a}$ group (OS: $19.7 \%$ vs. $25.3 \%, \mathrm{P}=0.221$, CSS: $22.6 \%$ vs. $30.1 \%, \mathrm{P}=0.092$ ) and $\mathrm{pN} 3 \mathrm{~b}$ group (OS: $19.7 \%$ vs. $19.6 \%$, $\mathrm{P}=0.349$, CSS: $22.6 \%$ vs. $23.5 \%, \mathrm{P}=0.452)$. Multivariable cox regression analyses in all patients also showed that TD was again associated with poor OS and CSS (Tables 4 and 5 , $\mathrm{P}<0.001)$.

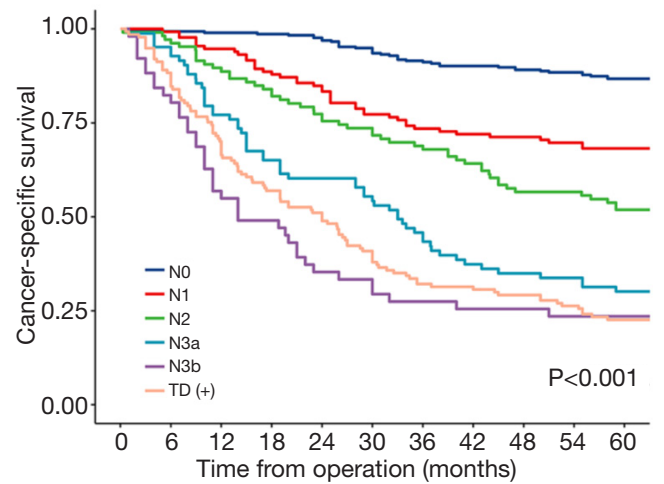

Figure 2 OS and CSS in all patients. OS, overall survival; CSS, cancer-specific survival. 
Table 4 Multivariable cox regression analyses of OS in all patients

\begin{tabular}{|c|c|c|c|c|}
\hline Variables & $\mathrm{HR}$ & $\begin{array}{c}95 \% \mathrm{Cl} \\
\text { lower }\end{array}$ & $\begin{array}{c}95 \% \mathrm{Cl} \\
\text { upper }\end{array}$ & $P$ value \\
\hline $\begin{array}{l}\text { Gender } \\
\text { (male vs. female) }\end{array}$ & 0.923 & 0.727 & 1.170 & 0.508 \\
\hline Age & 0.999 & 0.990 & 1.008 & 0.775 \\
\hline \multicolumn{5}{|l|}{ Tumor location } \\
\hline Lower & Ref & Ref & Ref & Ref \\
\hline Middle & 1.050 & 0.798 & 1.382 & 0.725 \\
\hline Upper & 1.224 & 0.959 & 1.562 & 0.105 \\
\hline $\begin{array}{l}\text { Tumor size } \\
(\geq 5 \text { vs. }<5 \mathrm{~cm})\end{array}$ & 1.269 & 1.016 & 1.585 & 0.036 \\
\hline $\begin{array}{l}\text { Differentiated } \\
\text { (high vs. low) }\end{array}$ & 1.427 & 1.131 & 1.800 & 0.003 \\
\hline Chemotherapy & 0.103 & 0.077 & 0.138 & $<0.001$ \\
\hline \multicolumn{5}{|l|}{ pT stage } \\
\hline $\mathrm{pT} 1$ & Ref & Ref & Ref & Ref \\
\hline рT2 & 1.962 & 0.971 & 3.965 & 0.06 \\
\hline рT3 & 5.270 & 2.733 & 10.163 & $<0.001$ \\
\hline pT4a & 6.288 & 3.265 & 12.110 & $<0.001$ \\
\hline pT4b & 9.972 & 5.017 & 19.818 & $<0.001$ \\
\hline \multicolumn{5}{|l|}{ pN stage } \\
\hline pNO & Ref & Ref & Ref & Ref \\
\hline pN1 & 5.862 & 3.732 & 9.207 & $<0.001$ \\
\hline $\mathrm{pN} 2$ & 6.401 & 4.169 & 9.827 & $<0.001$ \\
\hline $\mathrm{pN} 3 \mathrm{a}$ & 11.117 & 7.244 & 17.060 & $<0.001$ \\
\hline $\mathrm{pN} 3 \mathrm{~b}$ & 10.010 & 6.346 & 15.792 & $<0.001$ \\
\hline TD & 1.697 & 1.314 & 2.191 & $<0.001$ \\
\hline
\end{tabular}

OS, overall survival; HR, hazard ratio; $\mathrm{Cl}$, confidence interval; TD, tumor deposit.

\section{Discussion}

With the advances made in medicine, more attention is paid to the examination of the pathology of specimens after curative surgery of gastric cancer. In the pathological examination, an increasing number of lymph nodes, vascular invasion, nerve infiltration, and TDs were discovered and reported (11). Many studies had reported TD indicated worse prognosis in a variety of malignancies (12-14). However, the significance of TD in gastric cancer is still controversial.
Table 5 Multivariable cox regression analyses of CSS in all patients

\begin{tabular}{lcccc}
\hline Variables & $\mathrm{HR}$ & $\begin{array}{c}95 \% \mathrm{Cl} \\
\text { lower }\end{array}$ & $\begin{array}{c}95 \% \mathrm{Cl} \\
\text { upper }\end{array}$ & $\mathrm{P}$ value \\
\hline $\begin{array}{l}\text { Gender } \\
\text { (male vs. female) }\end{array}$ & 0.885 & 0.690 & 1.135 & 0.337 \\
Age & 1.001 & 0.991 & 1.010 & 0.873
\end{tabular}

Tumor location

$\begin{array}{lcccc}\text { Lower } & \text { Ref } & \text { Ref } & \text { Ref } & \begin{array}{c}\text { Ref } \\ \text { Middle }\end{array} \\ \begin{array}{l}1.032 \\ \text { Upper }\end{array} & 1.210 & 0.773 & 1.377 & 0.832 \\ \begin{array}{l}\text { Tumor size } \\ (\geq 5 \text { vs. }<5 \mathrm{~cm})\end{array} & 1.427 & 1.133 & 1.798 & 0.003 \\ \begin{array}{l}\text { Differentiated } \\ \text { (high vs. low) }\end{array} & 1.571 & 1.228 & 2.010 & <0.001 \\ \begin{array}{l}\text { Chemotherapy } \\ \text { pT stage }\end{array} & 0.149 & 0.114 & 0.195 & <0.001 \\ \text { pT1 } & & & & \\ \text { PT2 } & 1.527 & 0.723 & 3.224 & 0.267 \\ \text { pT3 } & 3.971 & 1.994 & 7.909 & <0.001 \\ \text { PT4a } & 4.251 & 2.154 & 8.388 & <0.001 \\ \text { pT4b } & 6.831 & 3.360 & 13.891 & <0.001\end{array}$

$\mathrm{pN}$ stage

$\begin{array}{lrrrr}\text { pN0 } & \text { Ref } & \text { Ref } & \text { Ref } & \text { Ref } \\ \text { pN1 } & 4.617 & 2.915 & 7.312 & <0.001 \\ \text { pN2 } & 5.765 & 3.733 & 8.904 & <0.001 \\ \text { pN3a } & 9.735 & 6.296 & 15.053 & <0.001 \\ \text { pN3b } & 8.861 & 5.570 & 14.096 & <0.001 \\ \text { TD } & 1.905 & 1.470 & 2.469 & <0.001\end{array}$

CSS, cancer-specific survival; HR, hazard ratio; Cl, confidence interval; TD, tumor deposit.

To analyze the effect of TD on the prognosis of gastric cancer, we used PSM analysis. This analysis method considers and eliminates potential factors that may have an impact on the outcomes, widely applied to multicenter cohort researches (15). In our study, we recorded the baseline data included age, tumor size, differentiated degree, gender, pT stage, $\mathrm{pN}$ stage and tumor location, chemotherapy, and there exist difference in these baseline data between TD group and non-TD group, which may affect the survival outcomes independently. After PSM, the quality of analysis has improved significantly with the 
elimination of the difference in baseline data.

There were a few of study focused on TD in gastric cancer. Lee $e t$ al. conducted a retrospective analysis of 653 patients with gastric cancer and found TDs in $23.9 \%$ of all patients, and regression analysis revealed that TDs were positively associated with synchronous gastric cancer metastases $(\mathrm{P}<0.01)$. The sensitivity of TD for predicting synchronous metastasis was $83.6 \%$, while its specificity was $82.3 \%$. In their study, multivariate analyses showed that TD is an independent risk factor that affects prognosis. Meanwhile, patients with TD suffered poor prognosis than patients without TD under neoadjuvant chemotherapy. Besides, patients with TD showed worse prognosis in $\mathrm{pN} 1, \mathrm{pN} 2, \mathrm{pN} 3$ subgroup, respectively. It significantly suggested that the worse survivals of patients with TD (16). Sun et al. investigated the effect of TD on TNM staging in gastric cancer, through studied 2,998 patients diagnosed gastric adenocarcinoma who underwent radical gastrectomy (8). There were 534 patients $(17.8 \%)$ observed with TD, survival analysis indicated that there is no statistical difference between the prognosis of patients with TD in pT1-4a stage and that of patients without TD but in pT4a stage, pointing that gastric cancer with TD should be treated as a $\mathrm{T} 4 \mathrm{a}$ disease. This was the first time to propose that TD is affected by the TNM staging of gastric cancer. However, the patient's group of their studies were associated 30 years, diagnostic and therapeutic approaches of gastric cancer have changed dramatically in these periods. Besides, in their study, some esophagogastric junction cancer patients included should be defined as esophageal carcinoma according to 8 th edition of TNM staging, which may influence the quality of their study. Anup et al. analyzed 1,250 patients undergoing radical gastrectomy for gastric cancer and TD was founded in $132(10.5 \%)$ patients (9). They also found that patients with TD obtained significantly poor survival outcomes than patients without TD in pT1-pT3 stage, but similar survival outcomes to patients without TD in pT4 stage, which proved that TDs were likely to be treated as the symbol of advanced gastric cancer.

Whether the TD should be incorporated in $\mathrm{pN}$ or should be considered in TNM staging in gastric cancer is controversial. To answer this question, we analyze the prognosis between patients with TD and patients without TD in $\mathrm{pN} 0, \mathrm{pN} 1, \mathrm{pN} 2, \mathrm{pN} 3$ stage, respectively. The results all showed the appearance of TD made for a worse prognosis on patients with gastric cancer; even the prognosis of patients with TD was comparable to patients with $\mathrm{pN} 3$ stage. Interestingly, there are $5(3.6 \%)$ cases with TD in pT1 stage and $15(10.9 \%)$ case with TD in pT2 stage. In Hye Seung Lee's study, only 2 cases of pT1 stage and 4 cases of
pT2 stages were found to have TD, accounting for only $0.9 \%$ of the total number of cases (16). These finds support the opinion that TD may be a manifestation of advanced gastric cancer.

At present, the formation mechanism of TD is not yet clear, and many hypotheses about the formation mechanism were continuously put forward, but no consensus has been reached between these various hypotheses. In 1935, when Gabriel reported on the discovery of $\mathrm{TD}$, it was thought to be the result of the dissemination of cancer cells along blood vessels. In recent years, some scholars suggested that TD may be an intermediate state of metastasis: On the path of lymphatic vessels between two lymph nodes, tumor cells grow up and form TD (17). Also, some scholars believed that TD is externally capsule invaded from the metastatic lymph nodes; the tumor cells invaded the vascular nerve bundles, and then grow into TD. TD also may be a peritoneal metastasis (18). However, it could not explain that patients with TD but have no lymphatic nodes metastasis. Sun et al. compared the prognosis between patients with TD and peritoneal metastasis, and found that the 5-year OS rate of patients with peritoneal metastasis is only $7.4 \%$, patients with TD had better prognosis than peritoneal metastasis $(\mathrm{P}<0.005)(8)$; On the other hand, peritoneal metastatic nodules are multiple and closely arranged, but the TD is scattered and larger than peritoneal metastatic nodules, it also can be irregular.

Interestingly, there are quite several patients with TD but have no peritoneal metastasis. Therefore, it is not likely to treat TD as a peritoneal metastasis. The appearance of TD is associated with vascular infiltration, neural infiltration, and lymphatic infiltration (19). In other words, the present of TD showed that the tumors had already metastasized through multiple pathways such as blood vessels, nerves, and lymph vessels. This also explains why TD could significantly affect the prognosis of gastric cancer, even comparable to patients in $\mathrm{pN} 3$ stage.

In the 5th edition of TNM staging system for colon and rectal cancer, TDs $>3 \mathrm{~mm}$ in diameter in the pericolic and perirectal fat without any lymphatic evidence was treated as a metastasis lymph node (20). After that, in the 6th edition TNM stages of colon and rectal cancer, a TD has the form and contour like a lymph node was treated as a metastasis lymph node (21). However, with more studies on the important prognostic value of TD reported after that (2-4). Finally, AJCC considers that TD should not be treated as a metastatic lymph node, but be included in $\mathrm{pN} 1 \mathrm{c}$ stage, this change also supported by many studies later (22-25). In the opinion of the 8th edition of TNM staging system (7), 
a TD was thought as a metastatic lymph node in gastric cancer. However, recording to the results of our study, the conclusion may not agree that. At first, many studies and our study all had proved TD was an independent prognostic factor. Secondly, the OS and CSS of patients with TD were comparable to patients in $\mathrm{pN} 3$ stage. Finally, TD is defined to have no evidence of lymphatic node. Therefore, we thought it could not fully reflect the prognostic value of a $\mathrm{TD}$ as a metastasis lymph node in gastric cancer, instead of that, TD should be considered as a classification separately, like the status of TD in 7th edition of TNM staging system for colon and rectal cancer.

The first limitation of this study is the shortage of PSM that we could not match the unrecorded factors which may affect the outcomes. Secondly, the study is a retrospective analysis and therefore, has the related weakness from it. At last, we did not analyze the correlation between number of TD and prognosis. Larger sample studies are needed to confirm this conclusion further.

\section{Conclusions}

TD has a marked impact on the prognosis of gastric cancer, even patients with TD had the same prognosis with patients in $\mathrm{pN} 3$ stage. Considering these results, we think a TD may not simply be treated as a metastatic lymph node, but it should be staged for independence.

\section{Acknowledgments}

We thank for all the patients and their families taking part in the study.

Funding: This study is supported by the National Nature Science Foundation of China, No. 81572925.

\section{Footnote}

Conflicts of Interest: The authors have no conflicts of interest to declare.

Ethical Statement: The authors are accountable for all aspects of the work in ensuring that questions related to the accuracy or integrity of any part of the work are appropriately investigated and resolved. All procedures performed in studies involving human participants were following the ethical standards of the institutional and national research committee and with the 1964 Helsinki declaration and its later amendments or comparable ethical standards. This study also has been approved by the ethics committee of Sun Yat-sen Memorial Hospital (ID: SYSECKY-KS-2018-039).

\section{References}

1. Gabriel WB, Dukes C, Bussey HJR. Lymphatic spread in cancer of the rectum. Br J Surg 1935;23:395-413.

2. Ono C, Yoshinaga K, Enomoto M, et al. Discontinuous rectal cancer spread in the mesorectum and the optimal distal clearance margin in situ. Dis Colon Rectum 2002;45:744-9.

3. Ueno H, Mochizuki H, Shirouzu K, et al, Actual status of distribution and prognostic impact of ex-tramural discontinuous cancer spread in colorectal cancer. J Clin Oncol 2011;29:2550-6.

4. Shimada Y, Takii Y. Clinical impact of meso-rectal extranodal cancer tissue in rectal cancer: De-tailed pathological assessment using whole-mount sections. Dis Colon Rectum 2010;53:771-8.

5. Edge SB, Fritz AG, Byrd DR, et al. AJCC cancer staging manual, 7th ed. New York: Springer, 2010:143-59.

6. Puppa G, Ueno H, Kayahara M, et al. Tumor deposits are encountered in advanced colorectal cancer and other adenocarcinomas: an expanded classification with implications for colorectal cancer staging system including a unifying concept of in-transit metastases. Mod Pathol 2009;22:410-5.

7. Amin MB, Edge SB, Greene FL, et al. AJCC Cancer Staging Manual. 8th ed. New York: Springer, 2017

8. Sun Z, Wang ZN, Xu YY, et al. Prognostic significance of tumor deposits in gastric cancer patients who underwent radical surgery. Surgery 2012;151:871-81.

9. Anup S, Lu J, Zheng CH, et al. Prognostic significance of perigastric tumor deposits in patients with primary gastric cancer. BMC Surg 2017;17:84.

10. In H, Solsky I, Palis B, et al. Validation of the 8th edition of the AJCC TNM Staging System for Gastric Cancer using the National Cancer Database. Ann Surg Oncol 2017;24:3683-91.

11. Ayca Ersen, Mehtat S. Unlu, et al. Tumor deposits in gastric carcinomas. Pathol Res Pract 2014;210:565-70.

12. Sarioglu S, Akbulut N, Iplikci S, et al. Tumor deposits in head and neck carcinomas. Head Neck 2016;38:E256-60.

13. Lee YC, Wu CT, Kuo SW, et al. Significance of extranodal extension of regional lymph nodes in 
surgically resected non-small cell lung cancer. Chest 2007;131:993-9.

14. Zhang HD, Tang P, Duan XF, et al. Extranodal metastasis is a powerful prognostic factor in patients with adenocarcinoma of the esophagogastric junction. J Surg Oncol 2013;108:542-9.

15. Rosenbaum P, Rubin D. The central role of the propensity score in observational studies for causal effects. Biometrika 1983;70:41-55.

16. Lee HS, Lee HE, Yang HK, et al. Perigastric Tumor Deposits in Primary Gastric Cancer: Implications for Patient Prognosis and Staging. Ann Surg Oncol 2013;20:1604-13.

17. Balch CM, Buzaid AC, Soong S, et al. Final version of the American Joint Committee on Cancer staging system for cutaneous melanoma. J Clin Oncol 2001;19:3635-48.

18. Ueno H, Mochizuki H, Tamakuma S. Prognostic significance of extranodal microscopic foci discontinuous with primary lesion in rectal cancer. Dis. Colon Rectum 1998;41:55-61.

19. Ueno H, Mochizuki H, Hashiguchi Y, et al. Extramural

Cite this article as: Tan J, Yang B, Xu Z, Zhou S, Chen Z, Huang J, Gao H, Zheng S, Wen L, Han F. Tumor deposit indicates worse prognosis than metastatic lymph node in gastric cancer: a propensity score matching study. Ann Transl Med 2019;7(22):671. doi: 10.21037/atm.2019.10.33
Cancer Deposits Without Nodal Structure in Colorectal Cancer. Am J Clin Pathol 2007;127:287-94.

20. Fleming ID, Cooper JS, Henson DE, et al. AJCC Cancer Staging Manual, 5th ed. New York: Wiley, 1997:83-90

21. Greene FL, Page DL, Fleming ID, et al. AJCC Cancer Staging Manual, 6th ed. New York: Wiley, 2002:113-24

22. Wünsch K, Müller J, Jähnig H, et al. Shape is not associated with the origin of pericolonic tumor deposits. Am J Clin Pathol 2010;133:388-94.

23. Nagtegaal ID, Knijn N, Hugen N, et al. Tumor Deposits in Colorectal Cancer: Improving the Value of Modern Staging-A Systematic Review and Meta-Analysis. J Clin Oncol 2017;35:1119-27.

24. Wei XL, Qiu MZ, Zhou YX, et al. The clinicopathologic relevance and prognostic value of tumor deposits and the applicability of N1c category in rectal cancer with preoperative radiotherapy. Oncotarget 2016;7:75094-103.

25. Qiu HB, Chen G, Keshari RP, et al. The extramural metastasis might be categorized in lymph node staging for colorectal cancer. BMC Cancer 2011;11:414. 